\title{
Measuring and Compensating for Deficits of Self-Regulation in School Children via Ambulatory Assessment
}

\author{
Ulrike Schwarz ${ }^{\star}$, Caterina Gawrilow \\ Eberhard Karls University, Tuebingen, Germany \\ *Corresponding author. E-mail: ulrike.schwarz@uni-tuebingen.de
}

Background. Children with deficits in self-regulation often perform worse in school and are less accepted by peers. However, self-regulation can be trained and developed by making detailed plans to achieve specific goals. One such strategy is WOOP (it includes thinking about wishes, outcomes, and obstacles, and creating a plan to achieve a goal), known in the literature as MCII, or ifthen plans.

Objective. Noting the encouraging results of the WOOP method, we aimed to evaluate whether WOOP has the potential to ameliorate self-regulation deficits on a day-to-day-level .

Design. In total, 49 school-aged children ( $M=11.2$ years, $S D=8.4$ months) were randomly assigned to one of two groups: 1) Condition 1, which underwent a WOOP intervention; and 2) Condition 2, which performed the intervention without contrasting obstacles and planning. The self-regulation abilities were assessed each day over an 18-day survey period by both the children themselves and their parents. ADHD symptom-severity was assessed as a proxy for self-regulation; specifically, we used six items from the Conners 3 scale and the German adaptation of the Brief Self-Control Scale.

Results. The children in both conditions demonstrated increased self-regulation, according to their self-reports at the beginning and end of the survey period. The parents reported different progressions of the two conditions over the survey period, but these did not differ significantly. In addition, both conditions are helpful to improve children's self-regulation in daily life.

Conclusion. Further research on implementing practicable interventions in schoolchildren's daily life is highly recommended.

\section{Keywords:} self-regulation; Mental Contrasting with Implementation Intentions (MCII); WOOP; ambulatory assessment 


\section{Introduction}

Self-regulation is an important skill that has cognitive, behavioral, and emotional influence on a person's wellbeing and achievement (Kanfer, Reinecker, \& Schmelzer, 2006). It helps individuals work toward long-term goals, regulate emotions according to the situation, plan the implementation and processing of tasks, and control impulses (Guderjahn, Gold, Stadler, \& Gawrilow, 2013; Hartig \& Kanfer, 1973; Sitzmann \& Ely, 2011). Self-regulation is particularly necessary in the learning of competencies and the acquisition of knowledge, since self-regulation in learning is associated with increased participation and attention in the classroom (Zimmerman, 1990). Not surprisingly, there is a negative correlation between selfregulation deficits and academic success, as well as with social inclusion (Tangney, Baumeister, \& Boone, 2004; Wirth, Reinelt, Gawrilow, \& Rauch, 2015). Given the central role of self-regulation in a variety of life-outcomes, any intervention which increases someone's self-regulation would be valuable for society.

One of the core components of self-regulation is the ability to "help people deal with resistance and conflict, such as with obstacles and temptations standing in the way of attaining desired future outcomes" (James, 1890, p.5, according to Oettingen \& Gollwitzer, 2015). One prominent instance of such self-regulation is the ability to forgo a small, immediate reward in order to obtain a larger, later reward. Mischel, Shoda, and Rodriguez (1989) studied children's self-regulation by first placing a marshmallow on the table in front of them. The children were then told that they could either eat the marshmallow immediately, or refrain from eating the marshmallow and, after an interval, receive a second marshmallow. Thus, the children had to deploy self-regulation in order to wait for the larger, later reward. Mischel, Shoda, and Rodriguez found that not all children were able to control themselves and wait for the greater reward. Interestingly, when these same children were tested again upon reaching adulthood, it was found that those who were able to exert selfregulation in childhood (i.e., wait for two marshmallows) were more successful, satisfied, and socially integrated as adults than those who did not (Mischel, 2014). Together, these findings suggest that the degree of self-regulation developed as a child has far-reaching implications for life-outcomes.

Attention deficit/hyperactivity disorder (ADHD), which is characterized by inattention, hyperactivity, and impulsivity, is one clinically relevant example of a deficit of self-regulation maintained over the lifetime of most of those affected (American Psychiatric Association, 2013). Children with ADHD symptoms are more likely to forget their homework, tend to perform worse in the classroom, and are more likely to drop out of school than children without ADHD symptoms (Langberg et al., 2010; Wirth et al., 2015). A common observation about these children is that they lack self-regulation, and this, in turn, often leads to strained student-teacher relationships (Millenet, Hohmann, Poustka, Petermann, \& Banaschewski, 2013; Willcutt et al., 2012). For example, a child with symptoms of ADHD interrupts others or walks around the classroom and talks, even though quiet work is ongoing. In summary, deficits in self-regulation are disadvantageous, since self-regulation is essential for the long-term pursuit of a desired outcome, and consequently for the achievement of one's goals (Churchill \& Jessop, 2010; Tangney, Baumeister, \& Boone, 2004). 
Self-regulation assists the achievement of goals by helping to bridge the gap between intention and behavior (see "The Intention-behavior Gap" Sheeran \& Webb, 2016). The phases for moving from intention to action, and thus closer to goal achievement and self-regulated action, are described in the action phase model (also known as the Rubicon model of action phases) (Gollwitzer, 1990; Gollwitzer, 2012; Heckhausen \& Gollwitzer, 1987). The action phase model illustrates the objective and aspiration, the path to action, and the plans that support self-regulated action (Achtziger \& Gollwitzer, 2010). Mental contrasting can help the individual more easily overcome the gap between wanting and doing.

Mental contrasting is a cognitive strategy investigated by Oettingen (2014); it is divided into two contrasting steps. In the first, the positive future associated with reaching the target is joyously anticipated, thus creating the expectation of success, and motivation to reach the target (Oettingen \& Mayer, 2002). For example, a student might have the idea that he wants to be more attentive in order to get better grades so that his parents will be proud of him, he will feel more comfortable overall, or he will be rewarded with a family trip if he graduates with good grades. In the second step of mental contrasting, a person thinks about obstacles in the here and now that stand in the way of this positive future, so that there is a discrepancy between the actual and the desired state, and a need to overcome the obstacles (Oettingen, Mayer, Thorpe, Janetzke, \& Lorenz, 2005). Out of this discrepancy arises the desire to change the current circumstances in order to come closer to the desired future (Oettingen, 2012). For example, this means that the student might realize that he is distracted by little things that happen outside his window. Now he could make a plan to act against this obstacle.

A plan helps to execute the action leading to the goal more consistently in the action phase, since the setting of the goal intention alone is not sufficient. In his research Gollwitzer (1999) is concerned with how these plans must be formulated in order to facilitate the achievement of objectives and the initiation of action. The most promising option seems to be to draw up an if-then plan, in addition to setting a goal. This takes the form of "IF situation X, THEN I show behavior Y" (Gollwitzer \& Brandstätter, 1997). In the if-then plan, the situation in which a goal-oriented behavior is to be adopted is explicitly addressed, so that a person recognizes this situation quickly as soon as he or she is in it, and can immediately implement the corresponding action (Gollwitzer, Fujita, \& Oettingen, 2004). It follows from this that a person does not have to search again for alternative actions - or for the energy to perform an action in the concrete situation - but can "stick to the plan" in a resource-conserving way (Schweiger Gallo \& Gollwitzer, 2007). The more frequently a person does this, the sooner the if-then plan, which links a situation to an action, no longer needs to be conscious; it becomes a habit (Parks-Stamm, Gollwitzer, \& Oettingen, 2007). For the previously mentioned inattentive student, this would mean that he would consciously follow the plan: "If I look distractedly out the window, then I think that learning is important and look at the teacher."

If-then plans have now been studied in a wide variety of applications and have been found to help people keep healthy diets and increased their physical activity (Achtziger, Gollwitzer, \& Sheeran, 2008; Gollwitzer \& Sheeran, 2006). Children with ADHD symptoms who show self-regulation deficits can use this strategy to act more appropriately and in a targeted manner (Gawrilow \& Gollwitzer, 2008), 
and improve their learning behavior (Gawrilow, Gollwitzer, \& Oettingen, 2011; Guderjahn et al., 2013)

In combination with mental contrasting, if-then plans are researched as Mental Contrasting with Implementation Intentions (MCII), also called by the acronym WOOP ${ }^{1}$ (Oettingen, 2014). WOOP combines the steps of both strategies by having the individual reflect on their wishes, outcomes, and obstacles, and finally formulate an if-then plan (Schweiger Gallo, Bieleke, Alonso, Gollwitzer, \& Oettingen, 2018). Using WOOP, participants show more self-discipline (Duckworth, Grant, Loew, Oettingen, \& Gollwitzer, 2011) and children with ADHD symptoms have more self-regulating abilities (Gawrilow, Morgenroth, Schultz, Oettingen, \& Gollwitzer, 2013). Students improve their performance so that, compared to the control group, which was taught only positive thinking as a strategy on the way to achieving goals, 5th graders who practiced WOOP improved their report card grades, their class attendance, and their behavior (Duckworth, Kirby, Gollwitzer, \& Oettingen, 2013).

In summary, there are indications that self-regulation deficits of children can be reduced by means of a WOOP intervention in the school context. For this reason, our study investigated whether WOOP has the potential to compensate for self-regulatory deficits associated with ADHD symptoms in everyday life. The two questions posed by the study were: 1) whether children who pursue their goals using WOOP (Condition 1) improve significantly more in their reported self-regulation from the first (pre) to the second (post) time of measurement than children in Condition 2, who only thought positively and did not mentally contrast $(\mathrm{H} 1)$; and 2) whether children who use WOOP (Condition 1) to pursue their goals show fewer fluctuations in their ADHD symptoms as reported daily by their parents than children in Condition 2 ( $\mathrm{H} 2)$.

\section{Methods}

The data collection was carried out by means of an ambulatory assessment design with measurement bursts (Sliwinski, 2008). Ambulatory assessment includes the recording of variables using portable devices directly in the everyday life of the study participants (Fahrenberg, Myrtek, Pawlik, \& Perrez, 2007).

\section{Participants}

All experimental procedures were considered and approved by the ethics committee of the German Society for Psychology and the Baden-Wuerttemberg Ministry of Culture. The participants $(\mathrm{N}=49,30$ female) were children (mean age 11.2, $\mathrm{SD} \pm 8.4$ months) who, at the time of the study, were in $5^{\text {th }}$ grade at seven schools in the German state of Baden-Wuerttemberg. Participants were recruited through a multi-step process, beginning with a nationwide call for volunteers via flyers and parent-teacher meetings. Participation in the experiment was incentivized by offering participating families a family excursion to an attraction of their choice (worth 40 euros) and writing materials. The assignment of the schools to the two conditions was randomized with the result that WOOP/ Condition 1 had 31 participants

1 which will be used below for this purpose. For further information see: woopmylife.org. 
$(\mathrm{M}=10.8$ years, $\mathrm{SD}=0.72,18$ girls $)$, and Condition 2 had 18 participants $(\mathrm{M}=11.2$ years, $\mathrm{SD}=0.37 ; 12$ girls).

\section{Materials}

In order to explain to the children all the necessary steps for creating an if-then plan, posters of the dimension 841 x $1189 \mathrm{~mm}$ were used for both the WOOP/ Condition 1 (experimental) and Condition 2 (control group). On the posters, all the steps necessary for creating the plan were listed with graphic support, which represented the pathway to the if-then plan as a hilly bicycle route.

\section{Measures}

Paper questionnaires were used in both conditions for the children to assess their own self-regulation both before and after the survey period. The questionnaire contained five items from the German version of the Self-Control Scale (SCS-K-D; Bertrams \& Dickhäuser, 2009) to measure self-regulation ability. The items were: "Sometimes I do things I regret later;" "I'm lazy;" "I'm good at pulling myself together;" "I'm good at resisting temptation;" and "I wish I had more self-discipline." The children were to indicate on a five-point-Likert scale to what extent these statements on self-regulation applied to them: " $1=$ completely inaccurate" to " $5=$ fits precisely." Inverted items of the scale were not reversed, but all the items that were not actually inverted were, so that consistently high values corresponded to a high degree of self-regulation. The total reliability was .47 (Cronbach's Alpha). The reliability of the individual items was between .28 and .52 (Cronbach's Alpha). A pilot study showed an increased ability to depict symptom fluctuations for the items used.

In addition, one parent of each participating child rated six items on their child's ADHD symptoms daily, between 8 p.m. and midnight, during the 18 -day measurement period. They used items from the Conners 3 scale (mean retest correlation at .79, from .75 - .83; Lidzba, Christiansen, \& Drechsler, 2013), which were reformulated for a daily survey; e.g., "Today my child had trouble organizing his business." (scale level " $1=$ not at all correct" to " $6=$ very accurate").

\section{Procedure}

The test procedure was identical for both conditions, except for the use of the respective materials. At the time of first contact at the school (intervention and pre-measurement), each investigator was assigned a group of a maximum of five children. The implementation leaders picked up the participating children in their classes and went with them to separate workrooms, which were provided by the school. The intervention took place there: as an introduction, the experimenter addressed the importance of having personal desires and goals, and of the children learning a strategy that helps them achieve their desires and goals. The information poster was then used to discuss the steps relevant to achieving their goals, and the children were asked at each step to think about how to take the step themselves. The children were then asked to work independently on the workbook they had been given out beforehand. The trainer was still available for answering compre- 
hension questions, and the standardized explanations in the manual were used to answer comprehension questions on individual steps.

The children were then given smartphones, which recorded additional data, which were not part of the present study (e.g., affect, media consumption), three times a day during the entire 18-day period, and reminded the children of their goals (e.g., "Learn more Spanish vocabulary for the next test.") on the 9th and 18th day. Afterwards the children were again verbally asked to think about their goal in the next days. During the second contact time at the school (post-measurement), after the 18 days, the participating children were picked up by implementation leaders during class time, and accompanied to a separate classroom where they completed the paper-questionnaire again in small groups (one implementation teacher took a maximum of five children, with a total group size from 3 to 19, depending on the school).

\section{Condition $1-$ WOOP}

On the poster of the experimental group, Step 1 was to formulate a goal relevant to what the child wanted to accomplish in school. The starting point comprised two questions: 1) "What is my wish for the school?" and 2) "Which goal do I want to reach in the next nine days?" Step 2 dealt with the desired state after the achievement of the goal and included the question: "What is the most beautiful thing when the goal has been achieved?" Step 3, a personal obstacle or difficulty that stands in the way of the child achieving the goal, was identified using two questions: "What prevents me from reaching my goal?" and "What stands in my way?" Step 4 involved formulating an alternative course of action with the question, "What can I do if the obstacle occurs?" This step was shown graphically on the poster as an alternative cycle path. Finally, the poster contained the if-then plan: "If the obstacle occurs, then I make/think behavior Y." (see Figure 1).

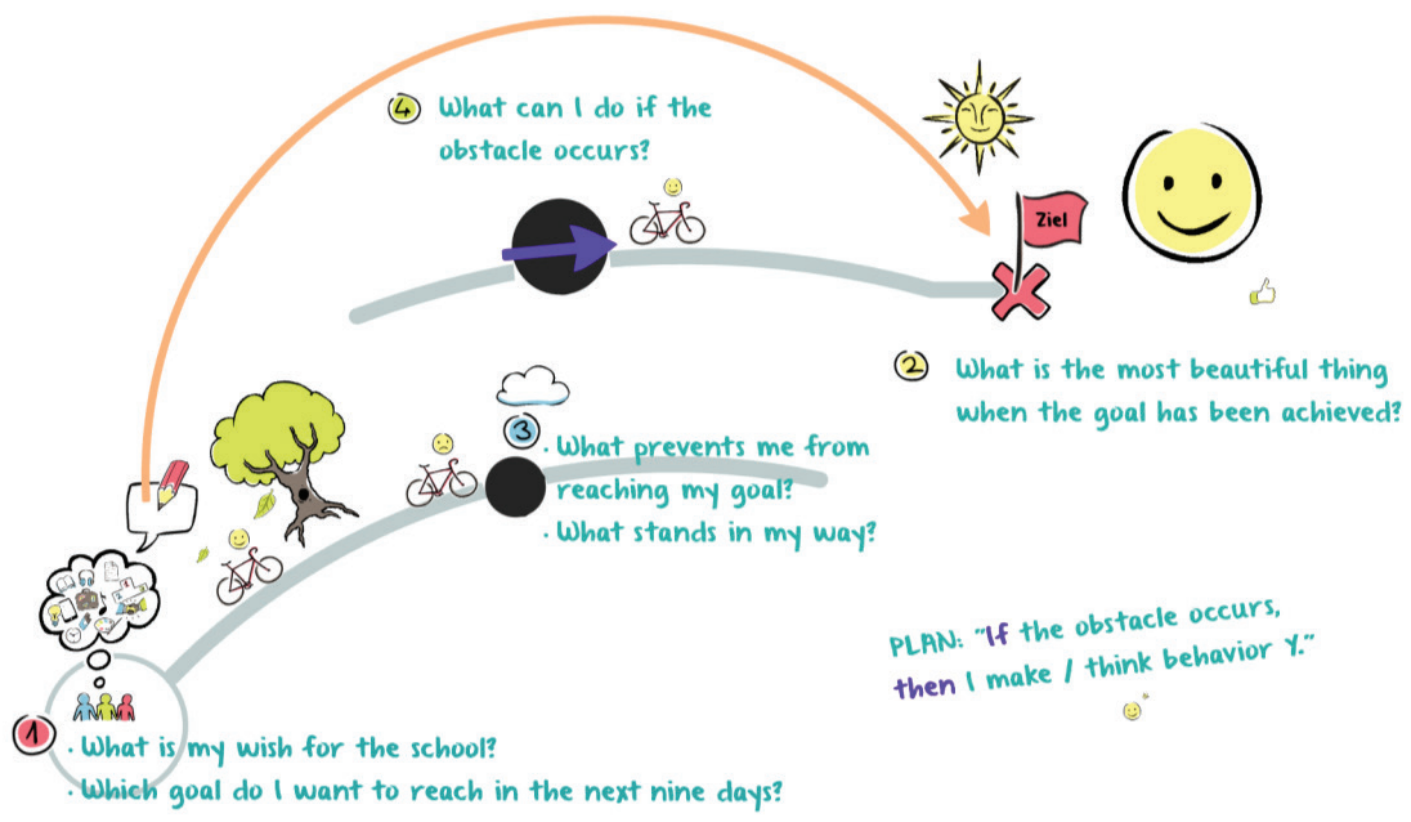

Figure 1. Poster WOOP/ Condition 1 (Used with permission from Prezi Inc.) 


\section{Condition 2 - without contrasting}

In order to keep the number of work steps the same in both groups, the poster of the control group also included four steps. The first and second steps were identical to that of the WOOP/Condition 1 (experimental group). The third step identified the feeling that arises after the achievement of the goal and included the question, "How do I feel when I have reached my goal?" The fourth step dealt with the condition after the achievement of the goal with the question, "What do I experience when I have achieved my goal?" Finally, the poster included the if-then plan, which is related to the feelings regarding the achievement of the goal: "If my goal is achieved, then the most beautiful thing happens and I feel X" (see Figure 2).

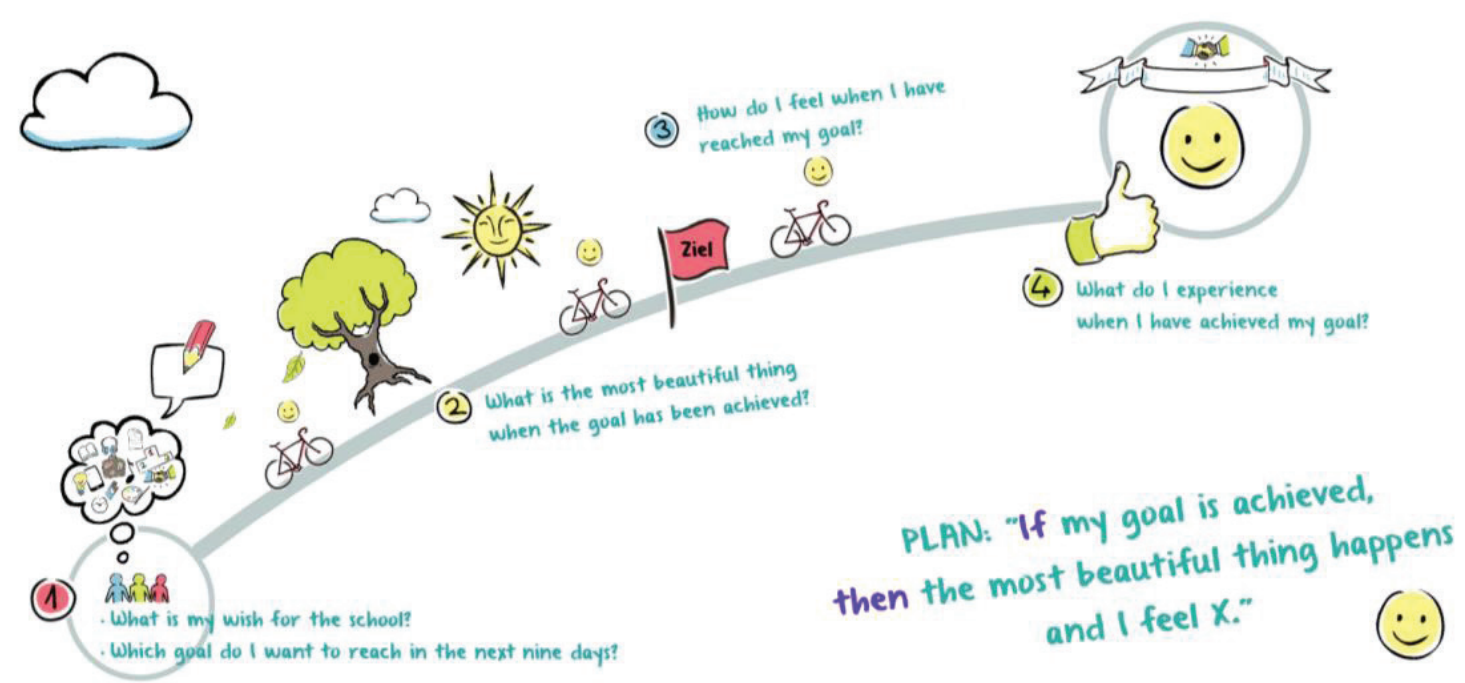

Figure 2. Poster Condition 2, without contrasting (Used with permission from Prezi Inc.)

In order to practice the creation of the if-then plan, workbooks (size of $148 \mathrm{x}$ $210 \mathrm{~mm}$ ) in which all four steps of the plan shown on the poster were listed again, one after the other, were issued to both groups. Under each step there was space for the independent written processing of the step. On the last pages of the workbooks, the children were asked to create an if-then plan ("Now I'm building my own ifthen plan, according to the template below!"): in the workbook of the WOOP/ experimental group, with respect to overcoming an obstacle, and in the control group, with respect to the feelings that arise when they have reached their destination. Thus, the children could fill these in individually, step by step, with their own answers.

\section{Results}

The preparation of the data for analysis was carried out using IBM SPSS Statistics 24 statistical software: If participants did not provide any information, and thus there were no answers to the variables to be evaluated, their data was completely removed from the data set and thus excluded from analysis. In total, there were two exclusions for the parent surveys and 14 exclusions of children's self-reports, due to their not answering any survey questions at one of the two measurement dates, or 
because of absence due to illness on the school survey date. The parents' data on the ADHD symptoms of their children were added together so that 36 represented the highest attainable total score. The actual data analysis was then performed with the analysis tool RStudio (version 3.3.0, 2016 - 05 - 03); the significance level was set at $p \leq .05$. Table 1 contains all amounts reported below.

First of all, we should report that no significant interaction between sex and time of measurement was found $(F(1,32)=1.29, p=.264)$. A significant main effect of the time of measurement was found $(F(1,32)=5.83, p=.022)$. Both sexes reported significantly higher self-control at the time of the second measurement than at the first time of measurement.

The first hypothesis $\left(\begin{array}{ll}\mathrm{H} & 1\end{array}\right)$ - that self-regulation would be improved by the WOOP/ Condition 1 compared to Condition 2 - was analyzed with an ANOVA, comparing the interaction of condition and point in time. No significant interaction was found between WOOP/Condition $1(n=16)$ and Condition $2(n=18)$ for the self-regulation reported by the children over time $(F(1,32)=1.33, p=.258)$. These results indicate that the conditions did not differ in their effect over time. However, a significant effect of the time of measurement was found $(F(1,32)=5.84$, $p=.022$ ), as depicted in Figure 3 (Condition 1: pre $M=3.36, S D=0.73$; post $M=3.50$, $S D=0.78$; Condition 2 : pre $M=3.44, S D=0.79$, post $M=3.84, S D=0.67)$. In both conditions, the children reported significantly higher self-regulation at the second time of measurement than at the first measurement time.

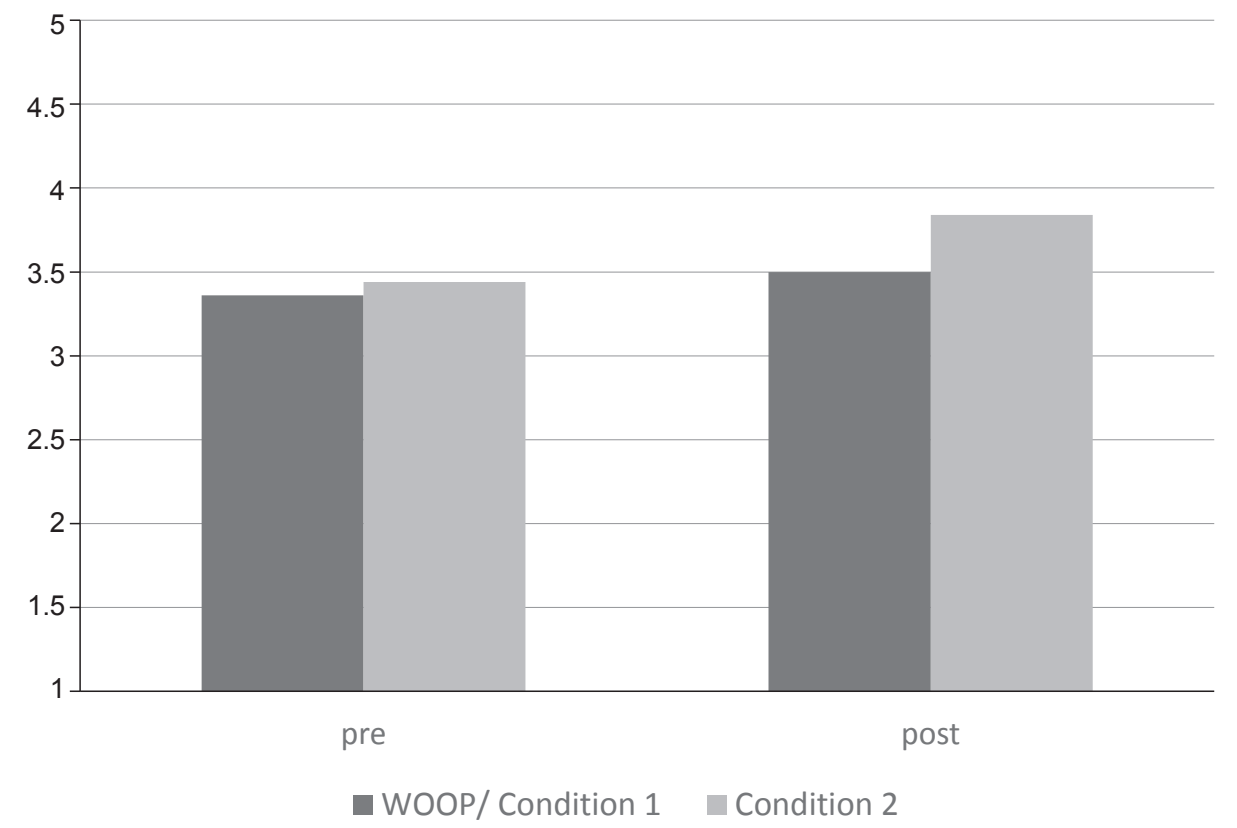

Figure 3. The average self-regulation of children as reported by themselves with the German version of the Self-Control Scale (Bertrams \& Dickhäuser, 2009) (y-axis, scale level 1-5), separated for the WOOP/ Condition 1 and Condition 2 at the measurement times pre and post survey (x-axis).

The t-test results on the assumption of hypothesis $2(\mathrm{H} 2)$ with regard to the ADHD symptoms of the children reported by the parents $(n=47)$, showed no significant difference for the mean values of the symptoms of all persons in both con- 
ditions over the 18 survey days, between WOOP/ Condition 1 and Condition 2 $(t=1.98, d f=39, p=.054 ; M$ Condition $1=11.59$, $M$ Condition $2=13.62)$. These results indicate that the conditions did not differ in their averages over time. This is shown in Figure 4. There was no major effect for the two conditions over time (Condition $1 F(1,27)=.616, p=.439$, Condition $2 F(1,16)=.12, p=.745)$, indicating that the parents reported on average no changes in their children's self-regulation on a daily basis, independent of conditions. However, the parents' reports on the ADHD symptoms of their children differed depending on which group their child belonged to (see also Figure 4). Participants in WOOP/ Condition 1 showed a less severe symptoms than participants in Condition 2. After checking the analysis for the standard deviations, we found that the scatter of values of the ADHD symptoms of all rated children of Condition 1 comparing to Condition 2 over the 18 survey days, were not significant $(t=1.96, d f=34, p=.057, M$ Condition $1=3.25$, $M$ Condition $2=4.42$ ). This suggests that on a person-to-person level, the parents' evaluations of the children of WOOP/ Condition 1, compared to Condition 2, did not differ significantly over the 18 survey days.
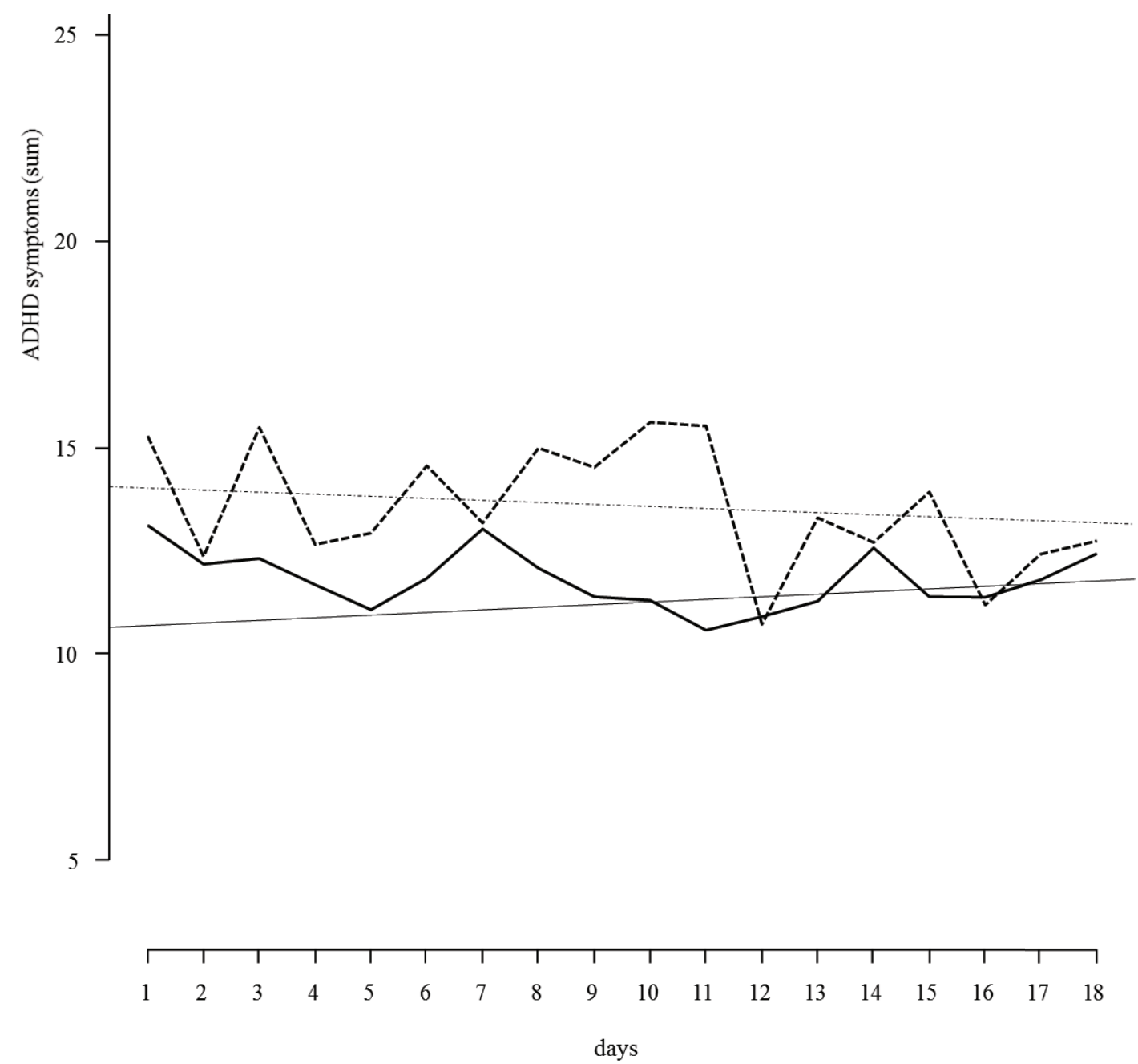

Figure 4. The children's ADHD symptoms reported by the parents with Conners 3 (Lidzba, Christiansen, \& Drechsler, 2013) over the 18 survey days, between WOOP/Condition 1 (continuous line) and Condition 2 (dashed line), and their respective mean value changes. 
The participating children all showed much joy during the intervention and seemed to enjoy the opportunity to talk about their wishes for achievement in school in the future. We controlled the commitment (meaning the motivation which is light by the goal) with the individually defined goals (e.g., "I would be disappointed not to achieve my goal."), for which there was no difference between the groups $(F(1,32)=.30, p=.588)$. This result suggests that the conditions did not differ in their respective motivation; they are comparable, and therefore the commitment could not be an explanation of the measured changes in children's self-regulation.

Table 1

Average self-regulation of children and the associated standard deviations, separated by groups and measurement times

\begin{tabular}{|c|c|c|c|c|}
\hline \multirow[b]{2}{*}{ Variable } & \multirow[b]{2}{*}{ Condition } & \multirow[b]{2}{*}{$n$} & \multicolumn{2}{|c|}{ Measurement } \\
\hline & & & $\begin{array}{c}\text { pre } \\
M(S D)\end{array}$ & $\begin{array}{c}\text { post } \\
\text { M (SD) }\end{array}$ \\
\hline \multirow{2}{*}{$\begin{array}{l}\text { self regulation } \\
\text { (self report) }\end{array}$} & WOOP/ Condition 1 & 16 & $3.36(0.73)$ & $3.5(0.78)$ \\
\hline & Condition 2 & 18 & $3.44(0.79)$ & $3.84(0.67)$ \\
\hline \multirow{3}{*}{$\begin{array}{l}\text { ADHD symptoms } \\
\text { (parents report) }\end{array}$} & & & \multicolumn{2}{|c|}{ Over all 18 days } \\
\hline & WOOP/ Condition 1 & 18 & \multicolumn{2}{|c|}{$11.59(3.25)$} \\
\hline & Condition 2 & 29 & \multicolumn{2}{|c|}{$13.62(4.42)$} \\
\hline
\end{tabular}

\section{Discussion}

This study aimed to determine whether a WOOP intervention could improve the children's self-regulation. To address this question directly, we trained children and recorded their own reports of their self-regulation, before and after an 18day survey period, as well as getting daily information from their parents assessing this ability. We found that children benefited from the WOOP intervention over time. Testing hypothesis 1 (H1) did not produce a significant result since WOOP/ Condition 1 did not lead to a significant improvement compared to Condition 2, which included no mental contrasting (one essential WOOP step). However, our study showed that children in both conditions improved significantly over time, as shown in pre-post comparison of their self-reported self-regulation.

This result is not in line with those of Saddawi-Konefka et al. (2017), who measured goal aspiration and learning towards a goal by means of WOOP, in comparison to a pure goal intention, and reported finding advantages for using WOOP. One possible explanation for the discrepancy between our results and those of Saddawi-Konefka et al., relates to the findings by Sevincer, Mehl, and Oettingen (2017) that participants often automatically mentally contrast, regardless of whether they were instructed to or not. This could be an explanation for the insignificant difference between the conditions, because mental contrasting is essential for training self-regulation (Oettingen, 2014). 
In the present study we did not examine whether individuals were able to mentally contrast themselves, so it could be that the children in Condition 2 also contrasted mentally and improved their self-regulation, and thus showed no difference compared to the children in Condition 1 . We suspect that the child-friendly materials which, in contrast to Saddawi-Konefka et al. (2017), not only differentiated between goal intention and WOOP, but resembled each other in two of the four steps, could have caused this (Condition 2 did not contrast in step 3, and in step 4 , the if-then plan didn't link the situation with the goal-oriented action, but only with a positive feeling toward the outcome).

A positive mood is positively related to the performance of an executive function task (which includes self-regulation, e.g., Gagne \& Nwadinobi, 2018) if the motivation for the task processing is high (Phillips, Bull, Adams, \& Fraser, 2002). So it is also conceivable that Condition 2 had a positive effect on the mood of the participating children, due to the increased positive connotation of the third training step, whereby the children's own abilities were assessed better than they would have been if they had had a neutral mind set.

Another aim of this study was to determine whether the children's daily ADHD symptom scores would be less variable in WOOP/Condition 1 as compared to Condition 2 ( $\mathrm{H}$ 2). Lower variability in ADHD symptoms might indicate that the WOOP at least engages the processes underlying self-regulation. We found no difference in the mean variability of ADHD symptom severity between the WOOP and non-WOOP conditions. However, the data show that consideration of a change in ADHD symptoms through self-regulation training may still be appropriate, as the curves are similar to the theoretically expected pattern of amplitude attenuation and reduction of daily variations in ADHD symptoms over time. ADHD symptoms vary in adolescents who are asked about them once a day (Schmid, Stadler, Dirk, Fiege, \& Gawrilow, 2016). Compensating for these symptoms by training children's underlying self-regulation abilities still seems to be conceivable and corresponds to considerations put forward by Barkley (2005), according to whom "ADHD represents a developmental disorder of behavioral inhibition that interferes with self-regulation and the organization of behavior torwards the future." (p. 3).

Our study was limited in several ways which may affect its interpretation. We figured that the daily confrontation with questions about one's own child may have sensitized the parents to the skills in question and distorted their judgments. Furthermore, the small sample size, especially when divided into the two conditions, means that the results shown cannot be generalized, since they lack statistical power.

A second limitation is the number of testing items used, since they were presumably too small, and therefore could not adequately represent the variables, which can also be deduced from the quality criteria. Besides, the construct of selfregulation is best represented by the overall scale (Lindner, Nagy, \& Retelsdorf, 2015). The idea behind our choice of test items was guided by the desire to keep the duration of the questioning as short as possible, especially since it was being done on a daily basis. In addition, a pilot study showed an increased ability to depict symptom fluctuations for the items used. For analyzing the results of the first 
hypothesis, we used the self-reported values of children on single items of the German version of the Self-Control Scale (Bertrams \& Dickhäuser, 2009). This could potentially limit the validity of the results, because the children might overrate their abilities (see Hughes, Turkstra, \& Wulfeck, 2009), and for this reason we recommend parents as raters of their children's self regulation.

\section{Conclusion}

In summary, the present study aimed to evaluate whether WOOP has the potential to reduce self-regulation deficits on a day-to-day-level. We found improvement in self-reported self-regulation for the children over time, but an decrease of selfregulation deficits measured as reduction in ADHD symptoms reported daily by the parents, was not observed. Although we did not get the expected result showing an advantage of the WOOP condition compared to Condition 2, the study showed that self-regulatory interventions can basically help school children formulate and better achieve their school goals, and improve their selfassessed self-regulation. Although this relationship should be investigated again using bigger samples, the results of the present study do indicate that children can benefit from a WOOP intervention. With regard to the usefulness of measuring variables on a daily basis and of using portable devices, the advantages of ambulatory assessments, as Bugl, Schmid, and Gawrilow (2015) recommend, should be emphasized once again: they offer methodological and practical advantages by directly capturing aspects of the participants' interest in the natural environment and mapping processes.

These results contribute to the idea of applying self-regulation strategies on a daily basis, and thus to school psychological practice dealing with children with self-regulation deficits. For the future, we recommend carrying out specific interventions to promote self-regulation in the school setting. This can be done directly by the teaching staff after a training course, or under guidance, and can be integrated into lessons due to the short duration of the intervention (Gawrilow, Guderjahn, \& Gold, 2013).

\section{Acknowledgements}

This research was supported by the DFG, German Research Foundation (Project No. 283324755). The longitudinal section included three measuring points of 18 days each, at which times the children, parents, and teachers were surveyed. The present study refers only to the second measurement period, which took place in spring 2018, as the training reported here was carried out for the first time in the course of the project (the first measurement period had not included a training session). We thank all the families and schools for their participation. In addition, we thank Marie Diekmann, Anne Eppinger-Ruiz de Zarate, Lea Igney, Rieke Köpke, Stephanie Natter, Nicolas Oberhauser, Anna Lena Schultz, Caroline Schurz, Jana Welkerling, and Swea Ziegler for their help with collecting, entering, and preparing the data of the second measurement period. We especially thank our team colleagues Merle Reuter and Jan Kühnhausen. 


\section{References}

Achtziger, A., \& Gollwitzer, P.M. (2010). Motivation und Volition im Handlungsverlauf [Motivation and volition in course of action]. In J. Heckhausen \& H. Heckhausen (Eds.), Springer-Lehrbuch. Motivation und Handeln: Mit 45 Tabellen [Springer-Textbook. Motivation and action: With 45 tables] (4th ed., pp. 309-335). Heidelberg: Springer. https://doi.org/10.1007/978-3-642-12693-2_12

Achtziger, A., Gollwitzer, P.M., \& Sheeran, P. (2008). Implementation intentions and shielding goal striving from unwanted thoughts and feelings. Personality \& Social Psychology Bulletin, 34(3), 381-393. https://doi.org/10.1177/0146167207311201

American Psychiatric Association. (2013). Diagnostic and Statistical Manual of Mental Disorders: American Psychiatric Association. https://doi.org/10.1176/appi.books.9780890425596

Barkley, R.A. (Ed.). (2005). ADHD and the nature of self-control. New York: Guilford Press.

Bertrams, A., \& Dickhäuser, O. (2009). Messung dispositioneller Selbstkontroll-Kapazitaet [Measurement of the dispositional capacity of self-control]. Diagnostica [Diagnostics], 55(1), 2-10. https://doi.org/10.1026/0012-1924.55.1.2

Bugl, P., Schmid, J., \& Gawrilow, C. (2015). Ambulantes Assessment in der Schule: Den schulischen Alltag erfahrbar machen. [Ambulatory assessment at school: Making everyday school life a tangible experience] Lernen und Lernstoerungen, [Learning and learning disorders] 4(4), 261-268. https://doi.org/10.1024/2235-0977/a000115

Churchill, S., \& Jessop, D. (2010). Spontaneous implementation intentions and impulsivity: Can impulsivity moderate the effectiveness of planning strategies? British Journal of Health Psychology, 15(3), 529-541. https://doi.org/10.1348/135910709X475423

Duckworth, A.L., Grant, H., Loew, B., Oettingen, G., \& Gollwitzer, P.M. (2011). Self regulation strategies improve self discipline in adolescents: Benefits of mental contrasting and implementation intentions. Educational Psychology, 31(1), 17-26. https://doi.org/10.1080/01443410.2010.506003

Duckworth, A.L., Kirby, T., Gollwitzer, A., \& Oettingen, G. (2013). From fantasy to action: Mental contrasting with implementation intentions (MCII) improves academic performance in children. Social Psychological and Personality Science, 4(6), 745-753. https://doi.org/10.1177/1948550613476307

Fahrenberg, J., Myrtek, M., Pawlik, K., \& Perrez, M. (2007). Ambulatory assessment - Monitoring behavior in daily life settings. European Journal of Psychological Assessment, 23(4), 206-213. https://doi.org/10.1027/1015-5759.23.4.206

Gagne, J.R., \& Nwadinobi, O.K. (2018). Self-control interventions that benefit executive functioning and academic outcomes in early and middle childhood. Early Education and Development, 29(7), 971-987. https://doi.org/10.1080/10409289.2018.1496721

Gawrilow, C., \& Gollwitzer, P.M. (2008). Implementation intentions facilitate response inhibition in children with ADHD. Cognitive Therapy and Research, 32(2), 261-280. https://doi.org/10.1007/s10608-007-9150-1

Gawrilow, C., Gollwitzer, P.M., \& Oettingen, G. (2011). If-then plans benefit executive functions in children with ADHD. Journal of Social and Clinical Psychology, 30(6), 616-646. https://doi.org/10.1521/jscp.2011.30.6.616

Gawrilow, C., Guderjahn, L., \& Gold, A. (2013). Stoerungsfreier Unterricht trotz ADHS: Mit Schuelern Selbstregulation trainieren - ein Lehrermanual. [Trouble-free teaching despite ADHD: Training selfregulation with students - a teacher's manual.] Muenchen, Basel: Ernst Reinhardt Verlag.

Gawrilow, C., Morgenroth, K., Schultz, R., Oettingen, G., \& Gollwitzer, P.M. (2013). Mental contrasting with implementation intentions enhances self-regulation of goal pursuit in schoolchildren at risk for ADHD. Motivation and Emotion, 37(1), 134-145. https://doi.org/10.1007/s11031-012-9288-3

Gawrilow, C., Schmitt, K., \& Rauch, W. (2011). Kognitive Kontrolle und Selbstregulation bei Kindern mit ADHS [Cognitive control and selfregulation in children with ADHD]. Kindheit und Entwicklung, [Childhood and development] 20(1), 41-48. https://doi.org/10.1026/0942-5403/a000039

Gollwitzer, P.M. (1999). Implementation intentions: Strong effects of simple plans. American Psychologist, 54(7), 493-503. https://doi.org/10.1037/0003-066X.54.7.493 
Gollwitzer, P.M. (2012). Mindset theory of action phases. In P.A.M. van Lange (Ed.), Handbook of theories of social psychology (pp. 526-546). Los Angeles, Calif.: Sage. https://doi.org/10.4135/9781446249215.n26

Gollwitzer, P.M., \& Brandstätter, V. (1997). Implementation intentions and effective goal pursuit. Journal of Personality and Social Psychology, 73(1), 186-199. https://doi.org/10.1037/0022-3514.73.1.186

Gollwitzer, P.M., \& Sheeran, P. (2006). Implementation intentions and goal achievement: A metaanalysis of effects and processes. Advances in Experimental Social Psychology, 38, 69-119. https://doi.org/10.1016/S0065-2601(06)38002-1

Guderjahn, L., Gold, A., Stadler, G., \& Gawrilow, C. (2013). Self-regulation strategies support children with ADHD to overcome symptom-related behavior in the classroom. Attention Deficit and Hyperactivity Disorders, 5(4), 397-407. https://doi.org/10.1007/s12402-013-0117-7

Hartig, M., \& Kanfer, F.H. (1973). The role of verbal self-instructions in children's resistance to temptation. Journal of Personality and Social Psychology, 25(2), 259-267. http://dx.doi.org/10.1037/h0033938

Heckhausen, H., \& Gollwitzer, P.M. (1987). Thought contents and cognitive functioning in motivational versus volitional states of mind. Motivation and Emotion, 11(2), 101-120. https://doi.org/10.1007/BF00992338

Hughes, D.M., Turkstra, L.S., \& Wulfeck, B.B. (2009): Parent and self-ratings of executive function in adolescents with specific language impairment. International journal of language \& communication disorders, 44, 901-916. https://doi.org/10.1080/13682820802425693

Kanfer, F.H., Reinecker, H., \& Schmelzer, D. (2006). Selbstmanagement-Therapie: Ein Lehrbuch fuer die klinische Praxis [Self management therapy: A textbook for clinical practice], 4, durchges. Aufl., Heidelberg: Springer.

Langberg, J.M., Arnold, L.E., Flowers, A.M., Altaye, M., Epstein, J.N., \& Molina, B.S.G. (2010). Assessing homework problems in children with ADHD: Validation of a parent-report measure and evaluation of homework performance patterns. School Mental Health, 2(1), 3-12. https://doi.org/10.1007/s12310-009-9021-x

Lindner, C., Nagy, G., \& Retelsdorf, J. (2015): The dimensionality of the Brief Self-Control Scale - An evaluation of unidimensional and multidimensional applications. Personality and Individual Differences, 86, 465-473. https://doi.org/10.1016/j.paid.2015.07.006

Millenet, S., Hohmann, S., Poustka, L., Petermann, F., \& Banaschewski, T. (2013). Risikofaktoren und fruehe Vorlaeufersymptome der Aufmerksamkeitsdefizit-/Hyperaktivitaetsstoerung (ADHS) [Risk factors and early precursor symptoms of attention deficit/hyperactivity disorder (ADHD)]. Kindheit und Entwicklung [Childhood and development], 22, 201-208. https://doi.org/10.1026/0942-5403/a000118

Mischel, W. (2014). The Marshmallow Test: Mastering self-control. New York, NY, US: Little, Brown and Co.

Mischel, W., Shoda, Y., \& Rodriguez, M. (1989). Delay of gratification in children. Science, 244(4907), 933-938. https://doi.org/10.1126/science.2658056

Oettingen, G. (2012). Future thought and behaviour change. European Review of Social Psychology, 23(1), 1-63. https://doi.org/10.1080/10463283.2011.643698

Oettingen, G. (2014). Rethinking positive thinking: Inside the new science of motivation. New York, NY: Current.

Oettingen, G., \& Gollwitzer, P.M. (2001). Goal setting and goal striving. In A. Tesser \& N. Schwarz (Eds.), The Blackwell handbook of social psychology (pp. 329-347). Oxford: Blackwell. https://doi.org/10.1002/9780470998519.ch15

Oettingen, G., \& Gollwitzer, P. (Eds.). (2015). Self-regulation in adolescence. New York: Cambridge University Press.

Oettingen, G., \& Mayer, D. (2002). The motivating function of thinking about the future: Expectations versus fantasies. Journal of Personality and Social Psychology, 83(5), 1198-1212. https://doi.org/10.1037/0022-3514.83.5.1198

Oettingen, G., Mayer, D., Thorpe, J.S., Janetzke, H., \& Lorenz, S. (2005). Turning fantasies about positive and negative futures into self-improvement goals. Motivation and Emotion, 29(4), 236-266. https://doi.org/10.1007/s11031-006-9016-y 
Parks-Stamm, E.J., Gollwitzer, P.M., \& Oettingen, G. (2007). Action control by implementation intentions: Effective cue detection and efficient response initiation. Social Cognition, 25(2), 248-266. https://doi.org/10.1521/soco.2007.25.2.248

Phillips, L.H., Bull, R., Adams, E., \& Fraser, L. (2002). Positive mood and executive function: Evidence from Stroop and fluency tasks. Emotion, 2(1), 12-22. https://doi.org/10.1037/1528-3542.2.1.12

Saddawi-Konefka, D., Baker, K., Guarino, A., Burns, S.M., Oettingen, G., Gollwitzer, P., \& Charnin, J.E. (2017). Changing resident physician studying behaviors: A randomized, comparative effectiveness trial of goal setting versus use of WOOP. Journal of graduate medical education, 9(4), 451457. https://doi.org/10.4300/JGME-D-16-00703.1

Schmid, J., Stadler, G., Dirk, J., Fiege, C., \& Gawrilow, C. (2016). ADHD symptoms in adolescents' everyday life: Fluctuations and symptom structure within and between individuals. Journal of Attention Disorders. https://doi.org/10.1177/1087054716629214

Schweiger Gallo, I., Bieleke, M., Alonso, M.A., Gollwitzer, P.M., \& Oettingen, G. (2018). Downregulation of anger by mental contrasting with implementation intentions (MCII). Frontiers in Psychology, 9, 1838. https://doi.org/10.3389/fpsyg.2018.01838

Schweiger Gallo, I., \& Gollwitzer, P.M. (2007). Implementation intentions: A look back at fifteen years of progress. Psicothema, 19(1), 37-42.

Sevincer, A.T., Mehl, P.J., \& Oettingen, G. (2017). Well self-regulated people use mental contrasting. Social Psychology, 48(6), 348-364. https://doi.org/10.1027/1864-9335/a000322

Sheeran, P., \& Webb, T.L. (2016). The intention-behavior gap. Social and Personality Psychology Compass, 10(9), 503-518. https://doi.org/10.1111/spc3.12265

Sitzmann, T., \& Ely, K. (2011). A meta-analysis of self-regulated leaming in work-related training and educational attainment: What we know and where we need to go. Psychological Bulletin, 137(3), 421-42. http://dx.doi.org/10.1037/a0022777

Sliwinski, M.J. (2008). Measurement-burst designs for social health research. Social and Personality Psychology Compass, 2(1), 245-261. https://doi.org/10.1111/j.1751-9004.2007.00043.x

Tangney, J.P., Baumeister, R.F., \& Boone, A.L. (2004). High self-control predicts good adjustment, less pathology, better grades, and interpersonal success. Journal of Personality, 72(2), 271-324. https://doi.org/10.1111/j.0022-3506.2004.00263.x

Willcutt, E.G., Nigg, J.T., Pennington, B.F., Solanto, M.V., Rohde, L.A., Tannock, R., ... \& Lahey, B.B. (2012). Validity of DSM-IV attention deficit/hyperactivity disorder symptom dimensions and subtypes. Journal of Abnormal Psychology, 121(4), 991-1010. https://doi.org/10.1037/a0027347

Wirth, A., Reinelt, T., Gawrilow, C., \& Rauch, W.A. (2015). Selbstkontrolle in der Schule: Der Zusammenhang von geringer Selbstkontrolle und schlechten Schulleistungen bei Kindern mit ADHS. [Self-regulation at school: The link between low self-regulation and poor school performance among children with ADHD.] Lernen und Lernstoerungen [Learning and learning disorders], 4(4), 245-259. https://doi.org/10.1024/2235-0977/a000114

Zimmerman, B.J. (1990). Self-regulated learning and academic achievement: An overview. Educational Psychologist, 25(1), 3-17. https://doi.org/10.1207/s15326985ep2501_2

Original manuscript received July 08, 2019

Revised manuscript accepted October 10, 2019

First published online November 15, 2019

To cite this article: Schwarz, U., Gawrilow, C. (2019). Measuring and Compensating for Deficits of Self-Regulation in School Children via Ambulatory Assessment. Psychology in Russia: State of the Art, 12(4), 8-22. DOI: 10.11621/pir.2019.0401 